\title{
HUBUNGAN PERILAKU CARING PERAWAT DENGAN TINGKAT KECEMASAN PADA PASIEN PRE OPERASI KATARAK DI RUANG KENANGA RSUD dr. H. SOEWONDO KENDAL
}

\author{
Dwi Nurahayu $^{1}$, Sulastri $^{2}$ \\ ${ }^{1,2}$ STIKES Muhammadiyah Kendal \\ Email : dewi.nurahayu78@gmail.com
}

\begin{abstract}
ABSTRAK
Perilaku caring perawat adalah tindakan peduli perawat terhadap pasien untuk memenuhi kebutuhan dasarnya. Tujuan penelitian ini untuk mengetahui hubungan antara perilaku caring perawat dengan tingkat kecemasan pada pasien pre operasi katarak di ruang Kenanga RSUD dr. H. Soewondo Kendal. Metode penelitian ini adalah analitik dengan pendekatan Cross Sectional. Sampel dalam penelitian ini sebanyak 60 responden yakni pasien pre operasi katarak dengan rentang usia 50-60 tahun. Teknik pengambilan sampel dalam penelitian ini adalah accidental sampling. Pengumpulan data menggunakan kuesioner Hamilton Rating Scale for Anxiety dan Caring Behaviour Assessment Tool. Hasil analisa univariat menunjukan bahwa 66,7 \% perilaku caring perawat masih pada kategori rendah dan $55 \%$ tingkat kecemasan pasien preoperasi dalam kategori normal. Analisa bivariate menunjukan nilai p-value adalah 0,001 ( $\mathrm{p}<$ 0.05). Sehingga dapat disimpulkan bahwa terdapat hubungan yang signifikan anatara perilaku caring perawat dengan tingkat kecemasan pada pasien pre operasi katarak di ruang Kenanga RSUD dr. H. Soewondo Kendal. Berdasarkan hasil penelitian, maka disarankan Rumah Sakit meningkatkan caring perawat sehingga pasien yang akan operasi mampu menurunkan kecemasannya, melalui pengadaan peraturan caring, disiplin waktu, dan sangsi bagi perawat yang memiliki perilaku caring yang rendah.
\end{abstract}

Kata Kunci : Perilaku Caring Perawat, Tingkat Kecemasan, Pre Operasi Katarak 


\begin{abstract}
The caring behavior of nurses is the nurse's care to the patient to meet their basic needs. The purpose of this study to determine the relationship between caring behavior of nurses with anxiety levels in patients pre cataract surgery in the room Kenanga RSUD dr. H. Soewondo Kendal. This research method is analytical with Cross Sectional approach. The sample in this study were 60 respondents ie patients pere cataract surgery with age range 50-60 years. The sampling technique in this research was accidental sampling. The data were collected using the Hamilton Rating Scale for Anxiety and Caring Behavior Assessment Tool questionnaires. The result of univariate analysis showed that 66,7\% caring behavior of nurse was still in low category and 55\% preoperative patient anxiety level in normal category.The bivariate analysiss how sthep-valueis0.001( $p$ <0.05). So it can be concluded that there is a significant relationship between the behavior of caring nurses with anxiety level in patients pre cataract surgery in the room Kenanga RSUD dr. H. Soewondo Kendal. Based on the results of the study, it is suggested Hospital improves caring nurses so that patients who will be able to reduce surgery anxiety, through the provision of caring rules, time discipline, and sanctions for nurses who have low caring behavior.
\end{abstract}

Keywords : Nurse caring Behavior, Anxiety Level, Pre Cataract Surgery

\section{PENDAHULUAN}

Katarak merupakan kekeruhan lensa mata yang timbul karena adanya gangguan metabolisme pada lensa. Hal ini mengakibatkan gangguan refraksi cahaya ke dalam retina. Masyarakat di daerah tropis sangat berisiko mengalami katarak karena paparan sinar ultra violet yang lebih banyak dari pada daerah sub tropis (Ilyas, 2014). Kecemasan adalah kekhawatiran yang tidak jelas dan menyebar, yang berkaitan dengan perasaan tidak pasti dan tidak berdaya (Stuart, 2013). Kecemasan dapat menyebabkan respon kognitif, psikomotor, dan fisiologis yang tidak nyaman, misalnya sulit berpikir logis, peningkatan aktivitas motorikagitasi, dan peningkatan tanda-tanda vital (Videbeck,2013). WHO memperkirakan jumlah ada 285 juta orang yang mengalami gangguan penglihatan di dunia,dimana 39 juta mengalami kebutaan dan 246 juta memiliki low vision. Terlepas dari kemajuan dalam teknik bedah di banyak negara selama sepuluh tahun terakhir, penyebab utama gangguan penglihatan di seluruh dunia adalah katarak (51\%), glaukoma $(8 \%)$, AMD (5\%), kebutaan pada anak dan kornea opacitiy (4\%), kesalahanrefraktivedikoreksi dan trakoma (3\%), dan diabetik retinopathy (1\%), idiopatik (21\%) (Kemenkes RI, 2014). Prevalensi katarak hasil pemeriksaan petugas enumerator dalam Riskesdas 2013 adalah sebesar $1,8 \%$, Prevalensi katarak tertinggi di Sulawesi Utara $(3,7 \%)$ diikuti oleh Jambi $(2,8 \%)$ dan Bali $(2,7 \%)$. Prevalensi katarak terendah 
ditemukan di DKI Jakarta (0,9\%) diikuti Sulawesi Barat $(1,1 \%)$. Masih banyak penderita katarak yang tidak mengetahui jika menderita katarak. Hal ini terlihat dari tiga terbanyak.

Alasan penderita katarak belum operasi hasil Riskesdas 2013 yaitu 51,6\% karena tidak mengetahui menderita katarak, 11,6\% karena tidak mampu membiayai dan $8,1 \%$ karena takut operasi. Di Jawa Barat prevalensi penderita katarak sebesar $1,5 \%$ dari jumlah penduduk Jawa Barat (Kemenkes RI, 2014). Satu-satunya terapi untuk penderita katarak adalah pembedahan yang bertujuan untuk memperbaiki visus atau tajam penglihatan. Pembedahan katarak dilakukan dengan mengambil lensa mata yang terkena katarak kemudian diganti dengan lensa implan atau Intra Okuler Lens (IOL). Sebanyak lebih dari 90\% operasi katarak berhasil dengan perbaikan fungsi penglihatan yang dinyatakan dengan perbaikan visus pasien pasca operasi. Sebagian besar pasien mencapai visus kategori baik yaitu 6/18-6/6 setelah empat sampai delapan minggu (Kusuma, 2013). Pembedahan atau operasi katarak merupakan salah satu stressor bagi pasien penderita katarak. Sebagaimana disampaikan Hawari (2013) yang menyatakan bahwa prosedur pembedahan merupakan salah satu stressor bagi individu yang akan menjalaninya. Dari tinjauan keperawatan jiwa tindakan operasi menimbulkan krisis situasi yaitu gangguan internal yang ditimbulkan oleh peristiwa yang menegangkan, mengancam dan meningkatkan kecemasan. Menurut Long (2014), tindakan operasi adalah salah satu bentuk terapi yang dapat merupakan ancaman, baik potensial maupun aktual terhadap tubuh, integritas dan jiwa seseorang yang dapat mencetuskan kecemasan pada diri pasien. Perilaku yang harus ditunjukan oleh perawat ketika melakukan proses asuhan keperawatan adalah caring. Caring merupakan salah satu bentuk pelayanan yang didalamnya terdiri dari kasih sayang, keramahan, dan suatu pendekatan yang dinamis dimana perawat bekerja untuk lebih meningkatkan kualitas dan kepedulian kepada klien (Muhlisin dan Ichsan, 2013). Leininger (1981) menekankan bahwa mengasuh (caring) adalah tema sentral dari asuhan keperawatan serta pengetahuan dan praktik keperawatan (Tomey, 2013). Perilaku caring perawat merupakan hal yang penting bagi pasien sebagai pengguna jasa dalam pelayanan keperawatan yang akanmembantu salah satu proses dari kesembuhan pasien itu sendiri (Suryani, 2012). Peran perawat saat ini lebih banyak terlibat aktif dan memusatkan diri pada tindakan cure seperti caradiagnostic dan pengobatan. Ilmu pengetahuan dan teknologi yang berkembang saat ini, menuntut melakukan peran ganda dalam menjalani tugas caring dan curing (Motowidlo SJ, 2013). Berdasarkan hasil penelitian yang telah dilakukan oleh Suryani, dkk (2011) dapat disimpulkan bahwa faktor yang yang berhubungan dengan persepsi pasien terhadap perilaku caring perawat di unit rawat inap umum di Rumah Sakit IMC 
Bintaro adalah kebutuhan caring dan perilaku caring perawat. Faktor lainnya, yakni karakteristik responden dan penerimaan diri tidak memiliki hubungan dengan persepsi pasien terhadap perilaku caring.mengenai persepsi pasien tentang perilaku caring dalam pelayanan keperawatan didapatkan bahwa pengetahuan perilaku caring perawat menurut pasien adalah perawat memberi perhatian lebih kepada pasien dan keluarga dan perilaku caring perawat yang dirasakan pasien adalah perawat aktif bertanya, berbicara lembut, memberi dukungan, responsive, terampil dan menghargai serta menjelaskan. Hasil penilitian lain oleh Wahyuni (2008) mengenai perilaku caring perawat di RS Haji Adam Malik didapatkan sebanyak $58 \%$ pasien menyatakan perawat berperilaku baik dan $42 \%$ pasien menyatakan perawat berperilaku cukup. Sedangkan menurut penelitian yang dilakukan oleh Tati Nurbiyati (2015) adalah persepsi pasien tentang perilaku caring perawat dalam pelayanan keperawatan di Ruang Maranata I ini menghasilkan dua tema yaitu pengetahuan perilaku caring perawat menurut pasien adalah perawat memberi perhatian lebih kepada pasien dan diangggap keluarga, perilaku caring perawat yang dirasakan pasien adalah perawat aktif bertanya, berbicara lembut, memberi dukungan, responsif, terampil dan menghargai sertamenjelaskan. Hasil penelitian yang telah dilakukan oleh Yasmini (2015) adalah terdapat hubungan antara caring perawat dengan kepuasan paisien. Berdasarkan hasil pengamatan peneliti saat praktek klinik di ruang Kenanga
RSUD Dr. H. Soewondo Kendal, didapatkan data perawatan pasien di ruang Kenanga yaitu antara bulan Januari-April 2017 sebanyak 680 pasien, dengan rata-rata jumlah pasien sebanyak 170 pasien setiap bulan. Hasil observasi melalui pengamatan peneliti, ditemukan bahwa sebagian besar perawat sudah menunjukkan sikap caring dalam pelayanannya, perawat tampak ramah dan terbuka kepada pasien maupun keluarga, tetapi pasien katarak di ruang Kenanga masih tampak mengalami kecemasan. Hal ini ditunjukkan dari 7 pasien terdapat 5 (71\%) pasien katarak cemas dengan tanda gelisah dan sering bertanya. Sedangkan 2 (29\%) pasien katarak tidak cemas. Berdasarkan fenomena diatas dan dari pengalaman peneliti saat mengikuti praktek klinik, peneliti tertarik untuk melakukan penelitian dengan judul "Hubungan Perilaku Caring Perawat Dengan Tingkat Kecemasan pada Pasien Pre Operasi Katarak di Ruang Kenanga RSUD Dr. H. Soewondo Kendal." METODE PENELITIAN Penelitian ini merupakan penelitian deskriptif korelatif dengan menggunakan pendekatan cross sectional. Populasi dalam penelitian ini adalah seluruh pasien preoperasi katarak di Ruang Kenanga RSUD dr. $H$. Soewondo Kendal. Teknik pengambilan sampel menggunakan teknik accidental sampling, dimana dalam penelitian ini sampel terdiri dari 60 responden. Alat pengumpulan data dalam penelitian ini menggunakan dua instrument uta yakni kuesioner Hamilton Rating Scale for Anxiety dan Caring Behaviour Assessment Tool. Penelitian ini 
dilakukan pada tanggal 20 Desember 20 Januari 2018 di Ruang Kenanga RSUD dr. H. Soewondo Kendal.

HASIL DAN PEMBAHASAN

\section{A. HasilPenelitian}

Hasil penelitian dengan judul "Hubungan Perilaku Caring Perawat dengan Tingkat Kecemasan Pasien Pre-Operasi Katarak di Ruang Kenanga RSUD Dr.
H. Soewondo Kendal" yang telah dilaksanakan terhitung mulai tanggal 20 Desember 2017 - 20 Januari 2018 terdiri dari analisis univariat dan analisis bivariat. Hasil tersebut akan diuraikan sebagai berikut :

\section{Analisa Univariat}

a. Gambaran Perilaku Caring Perawat di Ruang Kenanga RSUD Dr. H. Soewondo Kendal

Tabel 1.1

Distribusi Frekuensi Perilaku Caring Perawat di Ruang Kenanga RSUD dr. H. Soewondo Kendal $2017(n=60)$

\begin{tabular}{lcc}
\hline Perilaku Caring Perawat & Jumlah & Persentase \\
\hline Rendah & 40 & $66.7 \%$ \\
Tinggi & 20 & $33.3 \%$ \\
\hline Total & 60 & $100 \%$ \\
\hline
\end{tabular}

Sumber : Data Primer, 2018

Hasil analisa perilaku caring perawat pada 60 responden di Ruang Kenanga RSUD Dr. H. Soewondo Kendal menujukan perilaku caring perawat yang rendah lebih banyak dibandingkan yang tinggi, dimana 66,7 \% disebutkan memiliki perilaku caring yang rendah dan hanya 33,3\% saja yang memiliki perilaku caring yang tinggi.

b. Gambaran Tingkat Kecemasan Pasien Pre-Operasi Katarak di Ruang Kenanga RSUD Dr. H. SoewondoKendal

Table 1.2

Distribusi Frekuensi Responden Berdasarkan Tingkat Kecemasan Pasien Pre Operasi Katarak di Ruang Kenanga RSUD Dr. H. Soewondo Kendal $2018(n=60)$

\begin{tabular}{lcc}
\hline Tingkat kecemasan & Jumlah & Persentase \\
\hline Normal & 33 & $55 \%$
\end{tabular}




\begin{tabular}{lcc} 
Ringan & 25 & $41.7 \%$ \\
Sedang & 2 & $3.3 \%$ \\
Berat & 0 & $0.0 \%$ \\
Berat Sekali & 0 & $0.0 \%$ \\
\hline Total & 60 & $100 \%$
\end{tabular}

Sumber data Primer, 2018

Hasil analisa peringkat kecemasan pasien pre-operasi katarak pada 60 responden di Ruang Kenanga RSUD Dr. H. Soewondo Kendal menunjukan terdapat $55 \%$ pasien yang memiliki kecemasan normal, $41,7 \%$ yang mengalami kecemasan ringan dan hanya 3,3 \% yang memiliki kecemasan sedang, serta tidak ada yang memiliki kecemasan yang berat ataupun berat sekali.

\section{Analisa Bivariat}

Analisa bivariat dilakukan terhadap dua variabel yang diduga berhubungan atau berkorelasi yaitu Hubungan Perilaku Caring Perawat dengan Tingkat Kecemasan pada Pasien Pre Operasi Katarak di Ruang Kenanga RSUD dr. H. SoewondoKendal

Tabel 1.3 Distribusi Hubungan Perilaku Caring Perawat dengan Tingkat Kecemasan pada Pasien Pre Operasi Katarak di Ruang Kenanga RSUD dr. H. Soewondo Kendal 2018 $(n=60)$

\begin{tabular}{|c|c|c|c|c|c|c|c|c|}
\hline \multicolumn{9}{|c|}{ Perilaku caring } \\
\hline & & \multicolumn{2}{|c|}{ Rendah } & \multicolumn{2}{|c|}{ Tinggi } & \multirow[b]{2}{*}{$\mathrm{n}$} & & \multirow[t]{2}{*}{ Total } \\
\hline & & $\mathrm{n}$ & $\%$ & $\mathrm{n}$ & $\%$ & & $\%$ & \\
\hline Tingkat & Normal & 15 & 25 & 18 & 30 & 33 & 55 & 0,001 \\
\hline \multirow[t]{5}{*}{ Kecemasan } & Rendah & 24 & 40 & 1 & 1,7 & 25 & 41,7 & \\
\hline & Sedang & 1 & 1,7 & 1 & 1,7 & 2 & 3,3 & \\
\hline & Berat & 0 & 0 & 0 & 0 & 0 & 0 & \\
\hline & Berat & 0 & 0 & 0 & 0 & 0 & 0 & \\
\hline & Sekali & & & & & & & \\
\hline \multicolumn{2}{|c|}{ Total } & 40 & 66,7 & 20 & 33,3 & 60 & 100 & \\
\hline
\end{tabular}

Sumber : Data Primer, 2018

Analisa bivariat merupakan analisa yang dilakukan terhadap dua variabel yang saling berhubungan, yaitu untuk mengetahui hubungan antara perilaku caring dengan tingkat kecemasan. Jenis analisa yang digunakan dalam penelitian ini adalah uji chi square dengan tingkat signifikansi 0,05 . Setelah dilakukan penghitungan ternyata terdapat 2 sel $(33,3 \%)$ yang nilai harapannya kurang dari 5. Hal ini tidak memenuhi syarat chi square. Untuk mengatasi keterbatasan tersebut maka 
menggunakan uji alternatif Kolmogorof-Smirnov Test. Dari tabel 5.3 menunjukkan bahwa sebanyak 15 pasien pre operasi katarak (32\%) dengan tingkat kecemasan normal dan perilaku caring rendah, sedangkan 24 pasien pre operasi katarak (16\%) dengan tingkat kecemasan rendah dengan perilaku caring perawat rendah. Pasien pre operasi katarak yang mengalami tingkat cemasan sedang dengan perilaku caring rendag ada 1 orang $(1,7 \%)$. Terdapat 1 pasien pre operasi katarak (4\%) yang mengalami tingkat kecemasan sedangdengan perilaku caring tinggi.. Dari uji hipotesa menunjukkan nilai $\mathrm{p}$ value 0,001 (p value $<0,05$ ) yang berarti Ha diterima. Hal ini menunjukkan bahwa ada hubungan yang signifikan antara perilaku caring perawat dengan tingkat kecemasan pada pasien pre operasi katarak di ruang Kenanga RSUD dr. H. Soewondo Kendal.

\section{B. Pembahasan}

Hasil penelitian menunjukan bahwa ada hubungan yang signifikan antara perilaku caring perawat dengan tingkat kecemasan pada pasien pre operasi katarak di ruang Kenanga RSUD dr.H. Soewondo Kendal.

1.Gambaran Perilaku Caring Perawat diRuang Kenanga RSUD Dr. H. Soewondo Kendal Hasil penelitian menunjukan bahwa perilaku caring perawat di ruang Kenanga RSUDdr. H. Soewondo sebagian besar 40 (66.7\%) responden mengatakan rendah. Hanya $20(33.3 \%)$ responden yang mengatakan perilaku caring perawat tinggi. Seorang perawat harus dapat melayani pasien dengan sepenuh hati. Sebagai seorang perawat harus dapat memahami masalah yang dihadapi oleh klien, selain itu seorang perawat dapat berpenampilan menarik. Untuk itu seorang perawat memerlukan kemampuan untuk memperhatikan orang lain, ketrampilan intelektual, teknikal dan interpersonal yang tercermin dalam perilaku caring atau kasih sayang (Dwidiyanti, 2013). Caring sangatla $h$ penting untuk keperawatan. Caring adal ah fokus pemersatu untuk praktek keperawatan. Perilaku caring juga sangat penting untuk tumbuh kembang, memperbaiki dan meningkatkan kondisi atau cara hidup manusia (Blais, 2013). Sehingga seorang perawat dalam memberikan asuhan keperawatan harus mencerminkan perilaku caring dalam setiap tindakan. Maka kinerja perawat khususnya pada perilaku caring menjadi sangat penting dalam mempengaruhi kualitas pelayanan dan kepuasan pasien terutama di rumah sakit, dimana kualitas pelayanan menjadi penentu citra institusi pelayanan yang nantinya akan dapat meningkatkan kepuasan pasien dan mutu pelayanan (Potter \& Perry, 2013 ). Perilaku caring yang tinggi sangat penting dalam memberikan asuhan keperawatan karena dapat meningkatkan mutu asuhan keperawatan dan tercapainya pelayanan kesehatan yang optimal, sehingga kepuasan pasien maupun keluarga dapat tercapai. Sesuai dengan penelitian Abdul (2013) yang didapatkan hasil bahwa terdapat hubungan yang signifikan antara perilaku caring perawat dengan tingkat 
kepuasan pasien rawat inap rumah sakit. Peneliti berpendapat bahwa perilaku caring perawat yang dilakukan oleh perawat dapat dipengaruhi oleh beberapa faktor, salah satunya yaitu kepribadian yang sudah melekat di dalam diri perawat. Pernyataan tersebut didukung oleh teori Watson (2013) bahwa caring adalah suatu proses yang disengaja yang membutuhkan kesadaran diri, proses memilih, pengetahuan, keterampilan khusus serta pertimbangan waktu. Selain kepribadian, pengalaman dan pembelajaran juga dapat mempengaruhi terlaksananya perilaku caring perawat, karena pembelajaran melalui pendidikan dan pelatihan merupakan sarana penting bagi perawat dalam meningkatkan mutu pelayanan kesehatan khususnya dalam pemberian asuhan keperawatan. Skovholt (2005) dalam Kusmiran (2015) menyatakan bahwa aspek hubungan interpersonal caring meliputi pertukaran pengetahuan, pengalaman, kesabaran, kejujuran, rasa percaya, kerendahan hati, harapan dankeberanian.

\section{Gambaran Tingkat Kecemasan} Pasien Pre- Operasi Katarak di Ruang Kenanga RSUD Dr. H. SoewondoKendal Hasil penelitian sebagian besar mengalami tingkat kecemasan yang normal yakni 33 (55\%) responden, sedangkan sebagian lainnya mengalami tingkat kecemasan ringan 25 (41\%) responden dan sedang $2(3.3 \%)$ responden.

Kecemasan pasien adalah suatu kekhawatiran yang dialami pasien karena perawatan yang dialaminya di rumah sakit. Tingkat kecemasan sedang merupakan waktu yang optimal untuk mengembangkan mekanisme strategi koping pada pasien yang bersifat konstuktif melakukan tindakan proses keperawatan komunikasi terapeutik tetap harus berpegang pada konsep bahwa pasien adalah manusia yang bersifat unik dan kompleks yang dipengaruhi oleh faktor biopsikososial dan spiritual. Banyaknya alasan yang melatarbelakangi kecemasan pada pasien rawat inap baik alasan yang berupa : cemas menghadapi pembiusan, takut mati saat operasi, cemas menghadapi body image yang berupa cacat yang akan menganggu fungsi peran pasien, dan cemas masalah biaya perawatan. Peneliti berpendapat bahwa kecemasan ringan yang dialami sebagian responden disebabkan karena keparahan penyakit pasien yang tidak terlalu berat dan biaya perawatan yang sudah ditanggung oleh jaminan kesehatan. Pernyataan tersebut didukung oleh teori Morton (2013) bahwa pernyataan mengenai isu seperti situasi selama masa rawatinap, kembali bekerja, implikasi keuangan, kesejahteraan keluarga, dan keterbatasan. Stuart, Sundeen (2007) menjelaskan bahwa saat mengalami tingkat kecemasan sedang, seseorang akanlebih memusatkan pada hal-hal penting. Mereka mengesampingkan yang lain, sehingga perhatian pada hal yang selektif dan mampu melakukan sesuatu dengan lebih terarah. Terdapat $3,3 \%$ responden yang mengalami tingkat kecemasansedang. Hasil penelitian ini sejalan dengan hasil penelitian Sigalingging (2013) yang menunjukkan bahwa tingkat kecemasan 
keluarga pasien di ruang Intensif Rumah Sakit Columbia Asia Medan tergolong pada kategori berat yaitu 23 orang $(76,6 \%)$, kategori ringan yaitu 2 orang $(6,6 \%)$, artinya bahwa kecemasan pasien dan keluarga selama di ruang intensif banyak membutuhkan perhatian dan kepedulian perawat. Sehingga peneliti berpendapat bahwa peran perawat sangat berpengaruh terhadap tingkat kecemasan keluarga selama menunggu pasien di ruang intensif.

\section{Hubungan Perilaku Caring Perawat} dengan Tingkat Kecemasan pada Pasien Katarak di RuangKenanga RSUD dr. H. SoewondoKendal Berdasarkan hasil penelitian yang didapat menunjukkan bahwa sebanyak 15 pasien katarak pre operasi $(25 \%)$ dengan perilaku caring rendah dan tingkat kecemasan normal, sedangkan 18 pasien katarak pre operasi (30\%) dengan tingkat kecemasan normal mendapatkan perilaku caring perawat tinggi. Perilaku caring perawat dapat mempengaruhi tentang tinkat kecemasan pasien pre operasi katarak. Sebagian besar pasien pre operasi katarak mengalami tingkat kecemsan ringan dengan perilaku caring rendah ada $24(40 \%)$ responden. Sedangkan responden yang mengalami tingkat kecemasan ringan dengan perilaku caring tinggi ada $1(1.7 \%)$ responden. Berdasarkan rencana awal analisa bivariate menggunakan analisa chi square, akan tetapi hasil yang diperoleh terdapat 2 sel $(33,3 \%)$ yang memiliki nilai harapan $<5$. Untuk mengatasi keterbatasan tersebut maka peneliti menggunakan uji analisa bivariat alternative Kolmogorof-Smirnov Test
.Hasil akhir menggunakan uji analisa Kolmogorof- Smirnov Test adalah nilai $p$ value 0,001 . Hal ini menunjukkan bahwa hasil $\mathrm{p}$ value yang diperolehdiatas < 0,05, maka $\mathrm{Ha}$ diterima yang artinya ada hubungan yang signifikan(bermakna) antara perilaku caring perawat dengan tingkat kecemasan pasien pre operasi katarak. Hasil penelitian ini membuktikan bahwa tingkat kecemasan pasien preoperasi katarak dipengaruhi oleh perilaku caring perawat. Hal ini sesuai dengan teori bahwa perilaku caring perawat merupakan hal yang penting bagi pasien sebagai pengguna jasa dalam pelayanan keperawatan yang akan membantu salah satu proses dari kesembuhan pasien itu sendiri (Suryani, 2012). Akan tetapi peran perawat saat ini lebih banyak terlibat aktif dan memusatkan diri padatindakan cure seperti cara diagnostic dan pengobatan. Ilmu pengetahuan dan teknologi yang berkembang saat ini, menuntut melakukan peran ganda dalam menjalani tugas caring dan curing (Motowidlo SJ,2013). Beberapa penilitian terdahulu juga sejalan dengan penelitian ini diantaranya adalah penelitian yang dilakukan oleh Nurul Chotimah (2016) menunjukkan ada hubungan yang signifikan antara perilaku caring perawat dengan tingkat kecemasan keluarga pasien di ruang Intensive Care Unit (ICU) RSUD Tugurejo Semarang $\mathrm{p}$ value $<0,00001$ $(\alpha=0,05)$, dengan arah korelasi negatif dan tingkat kekuatan hubungan yang kuat $(\tau=-0,695)$, artinya semakin baik perilaku caring perawat maka semakin ringan tingkat kecemasan keluarga. 
Respon cemas bersifat kompleks dan bervariasi. Respon seseorang terhadap cemas bergantung pada jenis stresornya, kapan waktunya, bagaimana sifat orang yang mengalami kecemasan, dan bagaimana orang yang mengalami cemas bereaksi terhadap stresornya. Penerapan perilakucaring yang baik diharapkan kecemasan pasien dapat diminimalisir. Perawat harus sensitive terhadap kebutuhan maupun respon emosional pasien terhadap sakit maupun terhadap treatment (tindakan) yang dilakukan. Perawat dapat ,membantu mengurangi kecemasna dengan memberikan informasi yang lengkap dan tepat waktu. Menurut Kuotoukidis, Stainton \&Hughson (2013) perawat yang empati dan penuh perhatian secara signifikan dapat mengurangi kecemasan Hasil penelitian ini sejalan dengan penelitian Setiyawan (2014), menunjukkan bahwa ada hubungan yang signifikan antara perilaku caring perawat dengan tingkat kecemasan ibu akibat hospitalisasi anak di ruang rawat inap RSUD Ambarawa Kabupaten Semarang tahun 2014. Teori Anne Boykin menerangkan bahwa lingkungan caring yaitu membina hubungan keperawatan antara pasien maupun keluarga dan perawat dengan penuh perhatian, nilai, dan tindakan profesional (Kusmiran,2016). Menurut Potter \&Perry (2009) caring merupakan tindakan yang diarahkan untuk membimbing, mendukung individu lain atau kelompok dengan antisipasi kebutuhan untuk meningkatkan kondisi kehidupan seseorang. Tujuan dari caring adalah memberikan rasa aman dan nyaman terhadap seseorang, sehingga peneliti berpendapat bahwa dengan adanya perilaku caring perawat yang baik maka kecemasan yang dirasakan dapatberkurang.. Penelitian yang dilakukan oleh Hidayati (2013) didapatkan hasil bahwa terdapat hubungan yang signifikan antara perilaku caring perawat terhadap tingkat kecemasan pasien di Rumah Sakit PKU Muhammadiyah Surakarta. Hasil penelitian tersebut didukung oleh teori menurut Hawari (2011), bahwa penatalaksanaan kecemasan dapat dilakukan dengan psikoterapi,yang meliputi Suportif, re- edukatif, rekonstruksi, kognitif, psiko-dinamik, perilaku, keluarga, dan psikoreligius. Perilaku caring dapat dinyatakan sebagai suatu perasaan untuk memberikan keamanan, perubahan perilaku dan bekerja sesuai standar. Interaksicaring merupakan harapan dari penerima pelayanan kesehatan dalam proses perawatan (Duffy,2009). Peneliti berpendapat bahwa perilaku caring perawat dapat menurunkan tingkat kecemasan pasien. pasienakan merasa aman dan nyaman terhadap perawat karena pasien percaya bahwa ada orang yang dianggap lebih tau dan lebih mampu untuk mengatasi kondisinya yaitu kehadiran perawat. Pernyataan tersebut didukung oleh teori yang dikemukakan oleh Potter \&Perry (2009) tentang caring perawat yang meliputi aspek kehadiran, sentuhan kasih sayang, dan selalu mendengarkan. Hasil penelitian ditemukan bahwa terdapat responden yang menyatakan perilaku caring perawat dalam kategori tinggi namun mengalami tingkat kecemasan sedang, yaitu sebanyak 1,7\%. Hal ini 
kemungkinan disebabkan oleh faktorfaktor lain yang dapat menyebabkan kecemasan pasien. Dari keseluruhan responden hanya terdapat 1 responden yang menyatakan bahwa perilaku caring perawat dalam kategori rendah dan mengalami tingkat kecemasan sedang. Peneliti berpendapat bahwa kemungkinanpersepsi responden terhadap perilaku caring perawat dalam kategori rendah disebabkan karena pengalaman negatif terhadap perawat, sehingga pasien merasa tidak percaya terhadap perawat dan mengalami tingkat kecemasan sedang. Pernyataan tersebut didukung oleh teori Morton (2013) bahwa pengalaman negatif pasien dihubungkan dengan rasa takut, kecemasan, gangguan tidur, kerusakan kognitif, dan nyeri atau ketidaknyamanan. Hal ini sesuai dengan penelitian Meeboon (2006) bahwa pengalaman masa lalu akan memberikan pengaruh terhadap penilaian terhadap pelayanan yang akan diterima. Gunarsa (2007) menjelaskan bahwa tempat dan kondisi tertentu akanmempengaruhi suasana tertentu, dan suasana akan mempengaruhi kehidupan dan fungsional psikis seseorang. Sehingga peneliti menyimpulkan bahwa perawat sebagai pemberi asuhan keperawatan sangat penting untuk dapat mengembangkan aspek caring dalam memberikan asuhan keperawatan, agar tercipta suasana yang baik agar kenyamanan dapat dirasakan oleh pasien. Peneliti berpendapat bahwa aspek caring perawat di bangsal bedah sangat penting untuk dilakukan, mengingat bahwa bangsal bedah merupakan ruang untuk merawat pasien pre operasi maupun post operasi yang memerlukan perhatian berlebih terutama psikologinya yang akan melakukan tindakan operasi. Dewi (2014) menyatakan bahwa perawat sangat memegang peranan penting dalam memberikan asuhan keperawatan pada pasien yang sakit kritis atau keluarga secara menyeluruh baik biologi, psikologi, sosial, danspiritual.

\section{SIMPULAN DAN SARAN}

A. Simpulan Berdasarkan penelitian tentang hubungan perilaku caring perawat dengan tingkat kecemasan pada pasien pre operasi katarak di ruang Kenanga RSUD dr. H. Soewondo Kendal pada 20 Desember 2017 - 20 Januari 2018, maka dapat disimpulkan sebagai berikut:

1. Perilaku caring perawat yang rendah lebih banyak dibandingkan yang tinggi, dimana $66,7 \%$ disebutkan memiliki perilaku caring yang rendah dan hanya 33,3 \% saja yang memiliki perilaku caring yang tinggi.

2. Terdapat $55 \%$ pasien yang memiliki kecemasan normal, $41,7 \%$ yang mengalami kecemasan ringan dan hanya 3,3 $\%$ yang memiliki kecemasan sedang, serta tidak ada yang memiliki kecemasan yang berat ataupun berat sekali.

3. Terdapat hubungan yang signifikan antara perilaku caring perawat dengan tingkat 
kecemsan pada pasien pre operasi katarak di ruang Kenanga RSUD dr. H. Soewondo Kendal ( $p$-value $=$ $0,001<0,05$ (Ha gagal ditolak)).

\section{B. Saran.}

1. Perawat Hasil penelitian ini menunjukan bahwa perilaku caring perawat yang rendah $(66,7 \%)$ artinya masih lebih banyak dibandingkan dengan perilaku caring yang tinggi $(33,3$ $\%$ ), hal ini hendaknya dijadikan acuan bagi perawat untuk lebih meningkatkan perilaku caring perawat, dengan meningkatkan empatinya. Perilaku caring ini juga merupakan salah satu indikator pemberian pelayanan asuhan keperawatan yang berkualitas dan professional sehingga indikator ini perlu ditingkatkan guna meningkatkan kepuasan klien sebagai penerima jasa layanan di rumah sakit khususnya di ruang perawatan

2. Rumah Sakit Hasil penelitian ini perlu dicermati oleh pihak Rumah Sakit, diharapkan pihak RS Perlu melakukan upayaupaya peningkatan atau pembinaan kemampuan caring perawat sehingga pasien yang akan operasi khususnya operasi kaarak kecemasannya dapat berkurang

3. Pendidikan Lembaga pendidikan keperawatan hendaknya menekankan kemampuan perawat dalam melakukan caring keperawatan, sehingga ketika perawat telah bekerja memiliki kemampuan yang baik dalam berhubungan denganpasien.

4. Penelitiselanjutnya Hasil penelitian ini, seyogyanya dapat menjadi acuan atau dasar utuk penelitian yang sejenis guna pengembangan penelitian. khususnya penelitian guna meningkatkan kemampuan ataupun perilaku caring perawat melalui penelitian eksperimen.

\section{UCAPAN TERIMAKASIH}

Terimakasih kepada BAPPEDA Kabupaten Kendal, RSUD dr. H. Soewondo Kendal, Ibu Sulastri atas bimbingannya dalam penelitian, perpustakaan STIKes Muhammadiyah Pekajangan, Kedua Orang Tua beserta keluarga peneliti, Suami Tercinta dan Anak-anaku Tersayang.

\section{DAFTAR PUSTAKA}

Agus Riyanto. (2009). Aplikasi Metodologi Penelitian Kesehatan. Yogyakarta : Nuha Medika. Alimul, Aziz. (2007).

Metode Penelitian Kebidanan \& Tehnik Analisis Data. Jakarta : Salemba Medika Arikunto, S. (2006).

Prosedur Penelitian Suatu Praktik. Jakarta: Rineka Cipta. Baradero, Mary. (2008). Keperawatan Perioperative. Jakarta : EGC. Blais. (2013). 
Praktik Keperawatan Profesional Konsep Perspektif, Edisi 4. Jakarta:EGC. Dewi, Aliana. (2014).

Modul Pelatihan Keperawatan Intensif Dasar. Bogor: In Media. Durand, V. M, Barlow, D.H. (2017).

Essentials of Abnormal Psychology. Yogyakarta: Pustaka Pelajar Dwiyanti, M. (2013). Keperawatan Dasar: KOnsep Caring Etik dan Spiritual dalam Pelayanan Kesehatan. Semarang: Hasani Duffy, J.R. (2009).

Quality Caring in Nursing: Applying Theory to Clinical Practice, Education and Leadership. New York: Springer PublishingCompany. Ferrnsebner, billi. (2010).

Buku Ajar Keperawatan Perioperatif vo.2. Jakarta : EGC Gunarsa, S.D. (2007).

Konseling dan Psikoterapi. Jakarta: GunungMulia. Hawari, D. (2013).

Psikometri Alat Ukur (Skala) Kesehatan Jiwa. Jakarta:FKUI (2013).

Manajemen Stres, Cemas, dan Depresi. Jakarta: Fakultas Kedokteran Universitas Indonesia. Ilyas Sidarta. (2014). Ikhtisar Ilmu Penyakit Mata. Jakarta : Balai Penerbit Fakultas Kedokteran Indonesia Kemenkes RI, (2014)

Infodatin Situasi Gangguan Penglihatan Dan Kebutaan. Jakarta : Pusat Data Dan Informasi Kementrian Kesehatan Republik Indonesia. Koutoukidis, G., Stainton, K dan Hughson, J. (2013).
Tabbner's Nursing Care: Theory and Practice 6th edition. http://books.google.co.id.//. Diakses tanggal 22 November 2017 Kozier, Barbara et al. (2011).

Buku Ajar Fundamental Keperawatan: Konsep, Proses, dan Praktik. Jakarta:EGC. Kusmiran, Eny. (2015).

Soft Skills Caring DalamPelayanan Keperawatan. Jakarta: Trans InfoMedia. Kusuma, (2013).

Perbedaan Tajam Penglihatan Pasca Operasi Katarak Senilis Di RSUP. dr. Kariadi Semarang Periode 1 Januari 2007-31 Desember 2007 (Antara Operator Dokter Spesialis Mata Dan Calon Dokter Spesialis Mata Tahap Mandiri).

Artikel karya Tulis Ilmiah. Fakultas Kedokteran Universitas Diponegoro Semarang. Leininger, M. \& Mcfarland, M. R. (2002).

Transcultural Nursing :Concepts, Theories, Research and Practier. McGraw-Hill. New York: Natiional League for NursingPress (1991).

The Theory of Culture Care Diversity and Universality. New York: National League for NursingPress. Long, (2014).

Praktek Perawatan Medikal Bedah. Bandung : Ikatan Alumni Pendidikan Keperawatan Universitas Padjajaran. Meeboon, S. (2006).

The Effect of Patient and Nursing Unit Characteristics on Outcomes AmongHospitalized Patients with Chronic Illness in Thailand. A 
dissertation. Faculty of the college of nursing: The University ofArizona Morton, P.G. et.al. (2013).

Keperawatan Kritis, Pendekatan Asuhan Holistik, Vol.1. Jakarta: EGC. Motowidlo, S.J.. (2013).

Jobperformance. dalamBorman, W.C., Ilgen, D.R., Klimoski, Richard J.. (Ed.)Handbook of Psychology Volume 12 Industrial AndOrganizational Psychology. New York: Sage Publications. Muhlisin, A \& Ichsan, B. (2013).

Aplikasi Model Konseptual Caring Jean Warson dalam Asuhan Keperawatan. Berita Ilmu Keperawatan ISSN Nevid, J. F., dkk. (2015).

Psikologi Abnormal. Jakarta: Erlangga. Notoatmodjo (2010).

Metode Penelitian Kesehatan. Jakarta: RinekaCipta (2012).

Metode Penelitian Kesehatan. Jakarta: Rineka Cipta (2014).

Ilmu Perilaku Kesehatan. Jakarta: Rineka Cipta Nurachmah, E. (2011).

Asuhan Keperawatan Bermutu Di Rumah Sakit. Potter, P. A dan Peey, A. G. (2013).

Buku Ajar Fundamental Keperawatan: Konsep, Proses, dan Praktik Volume 1. Ed. 7. Jakarta :EGC Rothrock, JC.(2010).

Perencanaan asuhan keperawatan perioperatif. Jakarta :EGC. Saryono. (2010)
Metode Penelitian Kualitatif. Bandung: PT. Aslfabeta Setiawan, A. Dan Saryono.(2010).

Metodologi Penelitian Kebidanan. Nuha Medika:Jakarta Setiyawan, Dhika. (2014).

Hubungan Perilaku Caring Perawat Dengan Tingkat Kecemasan Ibu Akibat Hospitalisasi Anak (Usia0- 12 Tahun) Di Ruang Rawat Inap Anak Rsud Ambarawa Kabupaten Semarang. Skripsi. Program Studi Ilmu Keperawatan. STIKES Ngudi Waluyo.Ungaran. Sigalingging, Ganda. (2013).

Hubungan Komunikasi Terapeutik Perawat Dengan Tingkat Kecemasan Keluarga Pasien Di Ruang intensif Rumah Sakit Columbia Asia Medan. Medan: Darma Agung. Stuart, G. W. (2013).

Buku Saku Keperawatan Jiwa alih bahasa Ramona dan Egi. Jakarta: EGC. Sugiyono. (2012). Statistika untuk Penelitian. Bandung: CV Alfabeta. Suryani, M. (2014).

Persepsi pasien terhadap perilaku caring perawat di ruang rawat inap rumah sakit. Jakarta: Tesis.FKI UI Tomey, A. M \& Alligood, M. R. (2013).

Nursing Theorist and Their Work. United State of America: Mosby Udiyono, Ari. (2007).

Metodologi Penelitian Kesehatan. Semarang: Badan Penerbit Universitas Diponegoro. Untari, I dan Rohmawati (2014). 
"Faktor-Faktor Yang Mempengaruhi Kecemasan Pada UsiaPertengahan Dalam Menghadapi Proses Menua (Aging Process)". Surakarta : STIKES PKU MuhammadiyahSurakarta Videbeck, S.L. (2013).

Buku Ajar Keperawatan Jiwa. Jakarta: EGC. Watson, J. (2013).

Nursing ThePhilosophy and Science of Caring. Colorado: University Press of Colorado Wijayanti, Dewi. (2012).

Hubungan Antara Dukungan Keluarga Dengan Tingkat Kecemasan Pasien Pre Operasi di Bangsal Melati RSD Panembahan Senopati Bantul Yogyakarta. Diambil pada tanggal 09 September 2017 http://skripsistikes.wordpress.com/ Zaidin. (2012).

Dasar-dasar Keperawatan Profwsional. Jakarta: Widya Medika 